\title{
Performance Comparison of Reactive Power Controllers in Autonomous Wind-Diesel System
}

\author{
P. Sivachandran \\ Professor, Department of Electrical and Electronics Engineering, \\ Vel Tech Multi Tech Dr. Rangarajan Dr. Sakunthala Engineering College, \\ Chennai, India \\ E-mail: sivachandran@veltechmultitech.org
}

Received 9 April 2017; Accepted 23 June 2017;

Publication 18 August 2017

\begin{abstract}
This paper presents an automatic reactive power control of autonomous winddiesel hybrid power systems (AWDHPS) by artificial neural network (ANN) controller tuned static var compensator (SVC). The real time assessment of such control was carried out using dSPACE R \& D controller board. The proposed ANN controller was supported by multilayer perceptron artificial neural network (MPANN). The weights of proposed MPANN were restructured by intensive learning process. The back propagation equations were used to dynamically regulate the weights of proposed MPANN controller. Three models of AWDHPS were considered in the study. The disturbance parameters in the models were the change in reactive power of the load $(\Delta \mathrm{QL})$, the change in mechanical power input of the single induction generator $(\Delta \mathrm{PIW})$ and the change in mechanical power input of two induction generators ( $\Delta$ PIW1, $\Delta$ PIW2) respectively. The parameters were dynamically varied in control desk of dSPACE Software with DS1104 R \& D controller board mounted in personal computer under real time environment. The static and dynamic response curves were depicted. The reactive power deviations realized using the proposed MPANN controller was found to be very less compared to the deviations shown in ANN controller present in literature. The time domain
\end{abstract}

Journal of Green Engineering, Vol. 7, 1-24.

doi: 10.13052/jge1904-4720.7121

(c) 2017 River Publishers. All rights reserved. 
specifications of SVC obtained by the proposed MPANN controller were better than a Proportional plus Integral (PI) controller.

Keywords: dSPACE, Neural Networks, Reactive Power Control, WindDiesel System.

\section{Introduction}

The AWDHPS is becoming a viable and cost effective approach for remotely located communities [1]. In AWDHPS the wind energy system is the main constituent and diesel system forms the back up. The output of wind energy system with induction generator and diesel system with synchronous generator are connected to a common bus. The isolated loads not having access to main grid are connected to this common bus. This type of hybrid power system saves fuel cost, improves power capacity to meet the increasing demand and maintains the continuity of supply in the system [2]. The reactive power control of AWDHPS is based on the mathematical modeling of the system using power equations. The components of AWDHPS such as induction generator, synchronous generator, IEEE type - I excitation system and SVC are modelled individually to achieve their transfer functions. Then these transfer function blocks are combined together to build the MATLAB/Simulink model of the AWDHPS. These models of the AWDHPS were developed to perform the reactive power control under constant speed, variable speed and multi-wind diesel operations [3]. The SVCs are used to control the reactive power [4, 5].

The important characteristic of an ANN is its ability to solve an intricate problem very efficiently. Since the knowledge related to the problem is spread in the neurons and the connection weights of links between neurons the information are processed in parallel. The ANN has been applied to many power system problems $[6,7]$ and this shows that the ANNs have a great potential in power system applications. The ANN has been applied to tune the SVC over a wide range of load models [8]. The ANN play vital role in energy systems [9]. A $11 \mathrm{~kW}$ variable speed wind turbine control model is developed using MATLAB/Simulink and tested with dSPACE DS 1103 [10].

This paper presents the automatic reactive power control of AWDHPS by tuning SVC using the proposed MPANN. The MATLAB/simulink models of three different AWDHPS were built by integrating MPANN as the controller for tuning the SVC. The MPANN controller is illustrated with the input and back propagation equations and flowchart of algorithm. The performance of proposed MPANN controller was established by dynamical variation of the 
above disturbance parameters. Then MATLAB/simulink models of AWDHPS were built and assessed in dSPACE real time environment. The results such as reactive power deviations and time domain specifications were tabulated and discussed. The dSPACE real time response graphs of AWDHPS models are presented.

\section{AWDHPS Models Investigated}

The AWDHPS has been classified into three models based on the disturbance variables of the system.

AWDHPS Model - I: It is a Static Response Model (one variable). It is subjected to variation of change in reactive power of the load $(\Delta \mathrm{QL})$ alone.

AWDHPS Model - II: It is a Dynamic Response Model (two variables). It is subjected to variation of $\Delta \mathrm{QL}$ and change in mechanical power input of single induction generator ( $\triangle \mathrm{PIW})$.

AWDHPS Model - III: It is a Dynamic Response Model (three variables). It has two wind system and one diesel system. It is subjected to variation of $\Delta \mathrm{QL}$ and change in mechanical power input of two induction generators ( $\triangle$ PIW1, $\Delta$ PIW2).

The equations governing the reactive power control of AWDHPS are given below [3]. The change in system voltage due to reactive power disturbances of the AWDHPS is given by

$$
\Delta \mathrm{V}(\mathrm{s})=\frac{\mathrm{K}_{\mathrm{V}}}{1+\mathrm{sT}_{\mathrm{V}}}\left[\Delta \mathrm{Q}_{\mathrm{SG}}(\mathrm{s})+\Delta \mathrm{Q}_{\mathrm{SVC}}(\mathrm{s})-\Delta \mathrm{Q}_{\mathrm{L}}(\mathrm{s})-\Delta \mathrm{Q}_{\mathrm{IG}}(\mathrm{s})\right]
$$

where $\triangle \mathrm{QSG}$ is change in reactive power generated by $\mathrm{SG}$ (pu kVAR); $\triangle \mathrm{QSVC}$ is change in reactive power generated by SVC (pu kVAR); $\Delta \mathrm{QL}$ is change in reactive-power-load demand (pu kVAR); $\Delta$ QIG is change in reactive power required by IG generator (pu kVAR); KV is AWDHPS gain constant; TV is AWDHPS time constant in seconds.

The change in reactive power of the synchronous generator, induction generator and SVC are given by the Equations (2), (3) and (4) respectively.

$$
\begin{gathered}
\Delta \mathrm{Q}_{\mathrm{SG}}(\mathrm{s})=\mathrm{K}_{3} \Delta \mathrm{E}_{\mathrm{q}}^{\prime}(\mathrm{s})+\mathrm{K}_{4} \Delta \mathrm{V}(\mathrm{s}) \\
\Delta \mathrm{Q}_{\mathrm{IG}}(\mathrm{s})=\mathrm{K}_{7} \Delta \mathrm{V}(\mathrm{s})+\mathrm{K}_{6} \Delta \mathrm{P}_{\mathrm{IW}}(\mathrm{s}) \\
\Delta \mathrm{Q}_{\mathrm{SVC}}(\mathrm{s})=\mathrm{K}_{8} \Delta \mathrm{V}(\mathrm{s})+\mathrm{K}_{9} \Delta \mathrm{B}_{\mathrm{SVC}}(\mathrm{s})
\end{gathered}
$$


where $\triangle \mathrm{BSVC}$ is change in reactive susceptance of SVC; $\Delta \mathrm{E}$ ' $\mathrm{q}$ is change in internal armature emf under transient conditions of SG.

The exponent ( $\eta \mathrm{q})$ of reactive power load-voltage characteristic is determined by the equation,

$$
\eta_{\mathrm{q}}=\frac{\mathrm{V} \Delta \mathrm{Q}_{\mathrm{L}}}{\mathrm{Q}_{\mathrm{L}} \Delta \mathrm{V}}
$$

The simulink model of AWDHPS - III is shown in Figure 1. The three simulink models of AWDHPS were simulated in the MATLAB environment. The reactive power control performance was studied by applying the proposed MPANN controller and a proportional plus integral (PI) controller individually. The simulation was carried out using the AWDHPS data - I for AWDHPS Model - I and AWDHPS Model - II. The AWDHPS data - II was used for AWDHPS Model - III. The AWDHPS data and various constant values of

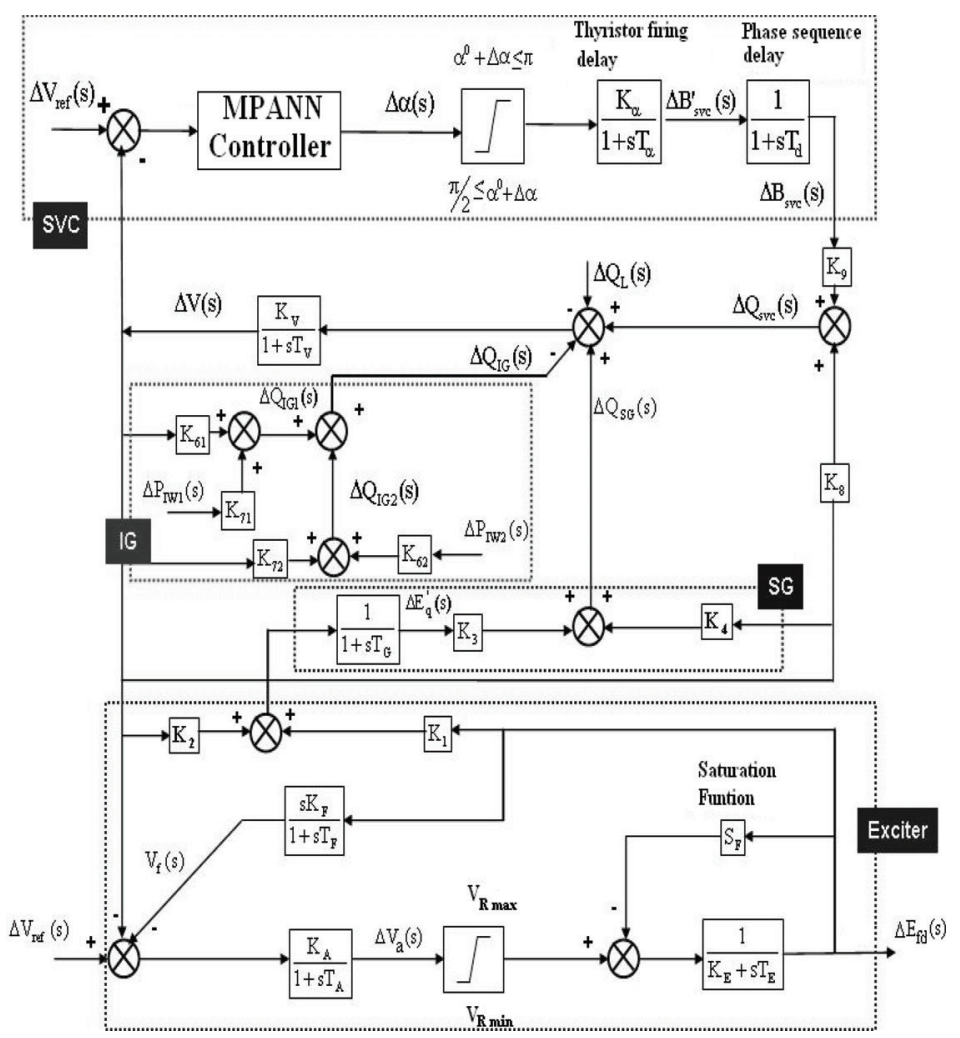

Figure 1 Simulink Model of AWDHPS Model - III. 
AWDHPS Models are given in the Appendix A and B respectively. Then the MATLAB/simulink models of AWDHPS were built in dSPACE real time environment. The disturbance parameters ( $\triangle \mathrm{QL}, \Delta \mathrm{PIW}, \Delta \mathrm{PIW} 1$ and $\Delta \mathrm{PIW} 2)$ are dynamically varied in control desk of dSPACE Software with DS1104 R \& D controller board mounted in personal computer under real time environment. The individual performance of proposed MPANN controller and PI controller in the above real time environment were recorded.

\section{MPANN Controller for Tuning of SVC}

The proposed multilayer perceptron artificial neural network (MPANN) controller consists of only one neuron in each layer and undergoes intensive learning for updating the weights. The non-linearity is imposed in the hidden layer alone by the log-sigmoid transfer function. The log-sigmoid function is taken because its output always lies between 0 and 1 .

Hence the control signal also lies between 0 and 1. As a result the output from hidden neurons is 0.5 when the input to the proposed MPANN is zero. The output from the hidden neurons with the output layer weights is established as a result of iteration. The output provides a control signal to make the steady state error as zero. The input and back propagation equations governing the MPANN controller are given below.

The change in system voltage and the change in reactive power load demand are the input (IC) to the proposed MPANN controller. It is given by Equation (6)

$$
\mathrm{IC}=\Delta \mathrm{V}+\Delta \mathrm{QL}
$$

The input (I) to the neurons of the hidden layer is given by following equation

$$
\mathrm{I}=\mathrm{IC} \times \mathrm{W} 1
$$

The output $(\mathrm{OH})$ from the hidden layer after passing into log-sigmoid transfer function is

$$
\mathrm{OH}=1 /(1+\mathrm{e}-\mathrm{I})
$$

The control signal (CS) from the output layer is determined by

$$
\mathrm{CS}=\mathrm{OH} \times \mathrm{W} 1
$$


The weights ( $\Delta \mathrm{W} 1)$ of the hidden layer are restructured by Equation (10)

$$
\Delta \mathrm{W} 1=(-1) \times \gamma \times \Delta 1+(\theta \times \Delta \mathrm{W} 1(\mathrm{PREV}))
$$

where $\Delta 1$ is derivative of the output of the hidden layer; $\gamma$ is learning rate: $\theta$ is momentum constant.

The weights $(\Delta \mathrm{W} 2)$ of the output layer are restructured by Equation (11)

$$
\Delta \mathrm{W} 2=(-1) \times \beta \times \mathrm{OH}+(\theta \times \Delta \mathrm{W} 2(\mathrm{PREV}))
$$

where $\beta$ is learning rate.

In AWDHPS Model-I, II and III the values of $\gamma, \beta$ and $\theta$ are $0.6,0.0001$ and -1 respectively. These values were achieved through trial and error method.

The derivative $(\Delta 1)$ of the output of the hidden layer with regard to its associated input weights is

$$
\Delta 1=\mathrm{OH} \times(1-\mathrm{OH}) \times \mathrm{IC}
$$

The flow chart of the algorithm is shown in Figure 2. The momentum constant, the learning rate of hidden layer and output layer are observed at first and

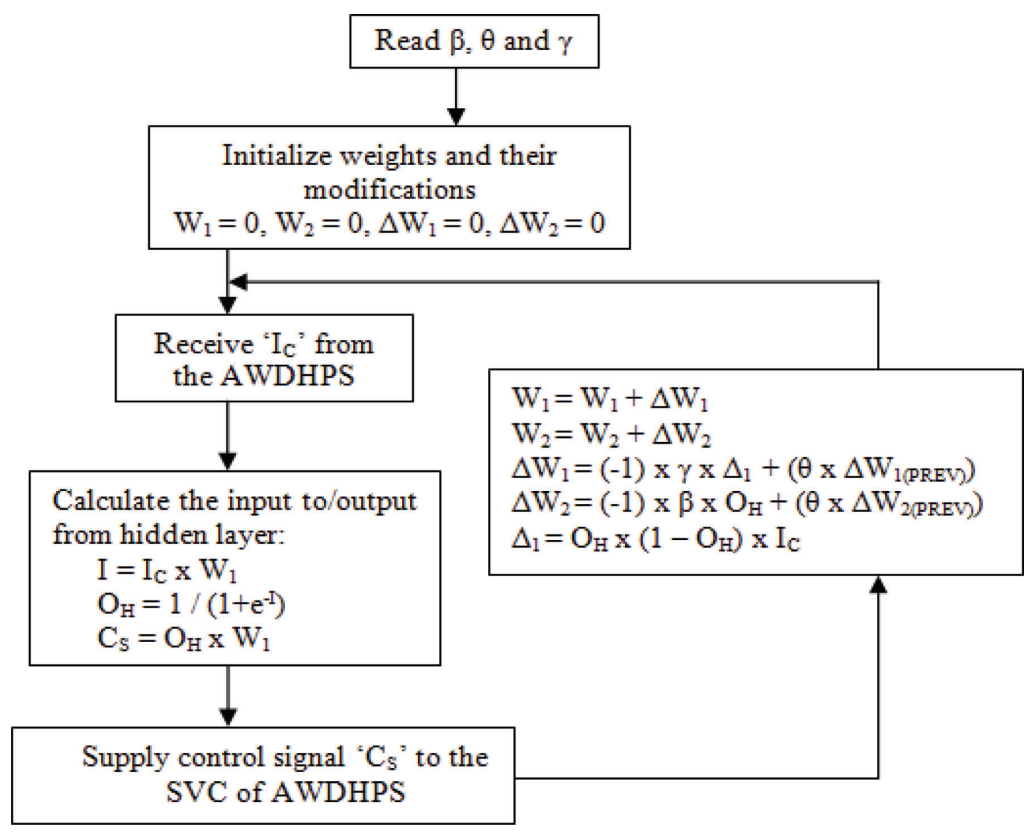

Figure 2 Flowchart of MPANN Control Process. 
the weights are initialized accordingly. The change in system voltage and change in reactive power load are obtained from AWDHPS. The input/output parameters of the hidden layer are calculated using the Equations (7), (8) and (9). The control signal is given to SVC for initiating reactive power control of AWDHPS. Depending upon the change in load and reactive power the weights of hidden layer and output layer are restructured using the Equations (10), (11) and (12).

\section{AWDHPS in dSPACE Environment}

The dSPACE system consists of three components: the DS1104 controller board mounted within a personal computer, a breakout panel for connecting signal lines to the DS 1104 controller board and software tools for operating the DS1104 controller board through the Simulink environment. The Real Time Interface data of AWDHPS Model - III is shown in Figure 3. Initially

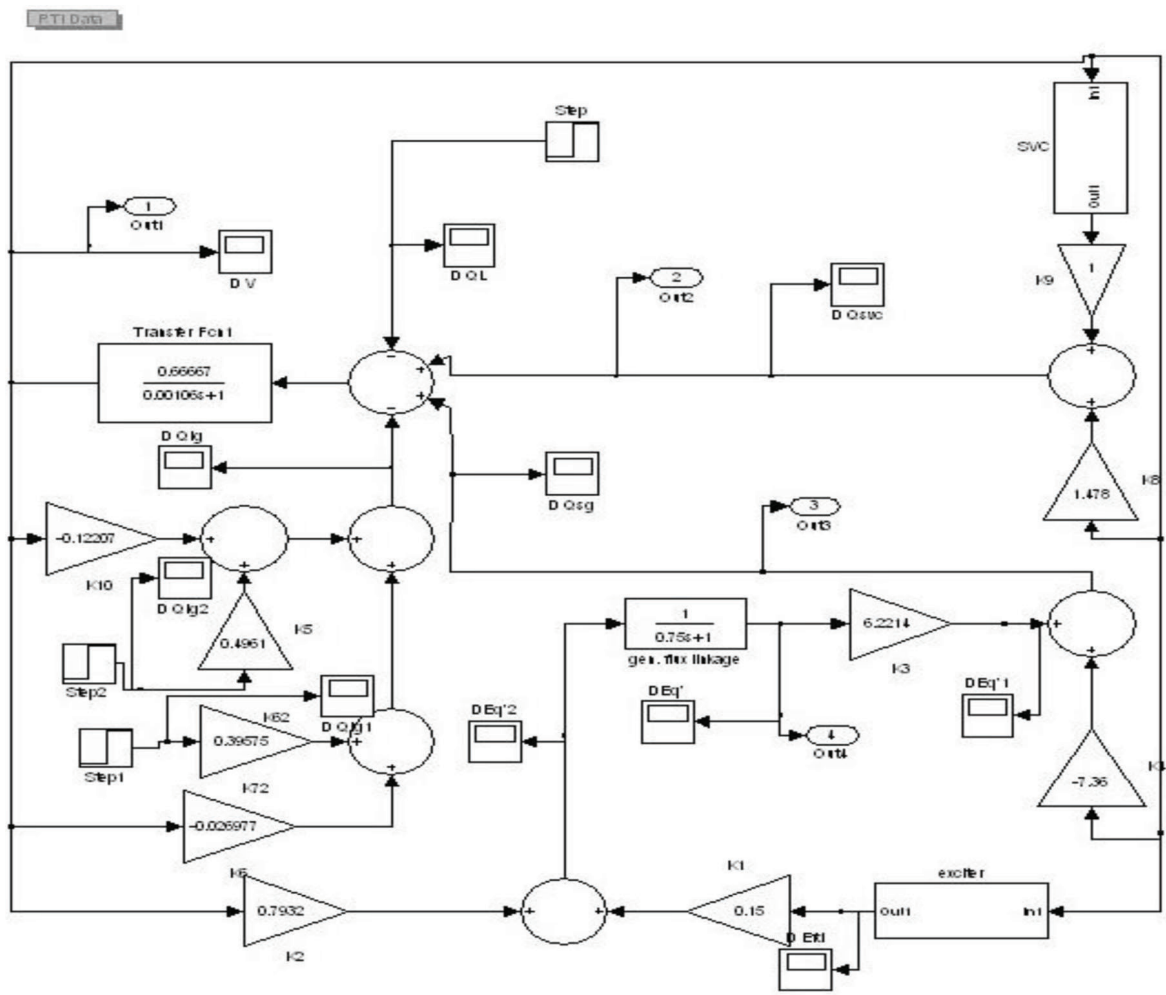

Figure 3 Real Time Interface Data of AWDHPS Model - III. 
the AWDHPS models with MPANN controller were prepared in Simulink as shown in Figure 1. The MPANN controller based Simulink models were built one by one in the Control Desk Software. During each build process, Matlab converts Simulink model into system description file (sdf). The sdf file consists of the code downloaded to the DS1104 Processor. The sdf file is used by dSPACE Control Desk to map the variables of the Simulink diagram to the variables displayed or controlled in the layout. After the building process, sdf file is transferred to control desk environment automatically. This file contains information of variables used in simulink model. These variables can be directly plotted using control desk software environment. Then a new layout file was started in control desk and the capture setting block from instrument panel was selected. The layout screen was drawn. Similarly a plotter array was selected. An appropriate variable was selected from down menu and dropped into the plotter block. Finally the animation mode was started and the variation of variables was observed on the plotter array. The information was saved in mat file version using capture setting window.

\section{Reactive Power Deviations}

The simulink models used in the study are referred from [3]. The parameters used are given in Appendix A and B. The three AWDHPS Models are implemented as per the discussion given in Section 4. Even though the time span of entire analysis is large it is possible to observe the performance curve variations within a time span of $0.01 \mathrm{sec}$ using the dSPACE environment. Hence a clear visual representation of the performance curves for smaller time span $(0.01 \mathrm{sec}$.) is depicted in Figures 4 (a to e), 5 (a to e) and 6 (a to e). The static and dynamic real time response curves of AWDHPS Models - I, II and III obtained by proposed MPANN for a wide variation of the disturbance parameters $(\Delta \mathrm{QL}, \Delta \mathrm{PIW}, \Delta \mathrm{PIW} 1$ and $\Delta \mathrm{PIW} 2)$ are shown in Figures 4,5 and 6 respectively. In [3], the maximum deviations of various parameters $(\Delta \mathrm{V}$, $\Delta$ QSG, $\Delta$ QSVC and $\Delta$ QIG) obtained through ANN in MATLAB/simulink environment are given for AWDHPS Models - II and III (with $\eta q$ values 3.25 and 1.25) only and not for AWDHPS Model - I. The maximum deviations of the parameters of AWDHPS Models - II and III obtained by the proposed MPANN controller in dSPACE environment for the same values of $\eta q$ were compared with [3] in Tables 1 and 2 respectively in order to establish its performance. The change in system voltage $(\Delta \mathrm{V})$ is significantly reduced by the proposed MPANN controller. 
Performance Comparison of Reactive Power Controllers in Autonomous

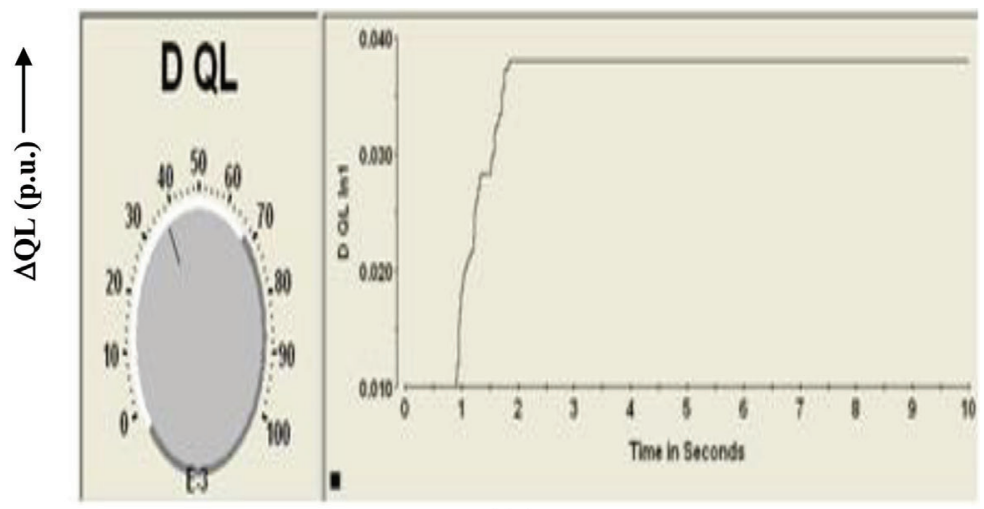

4(a)
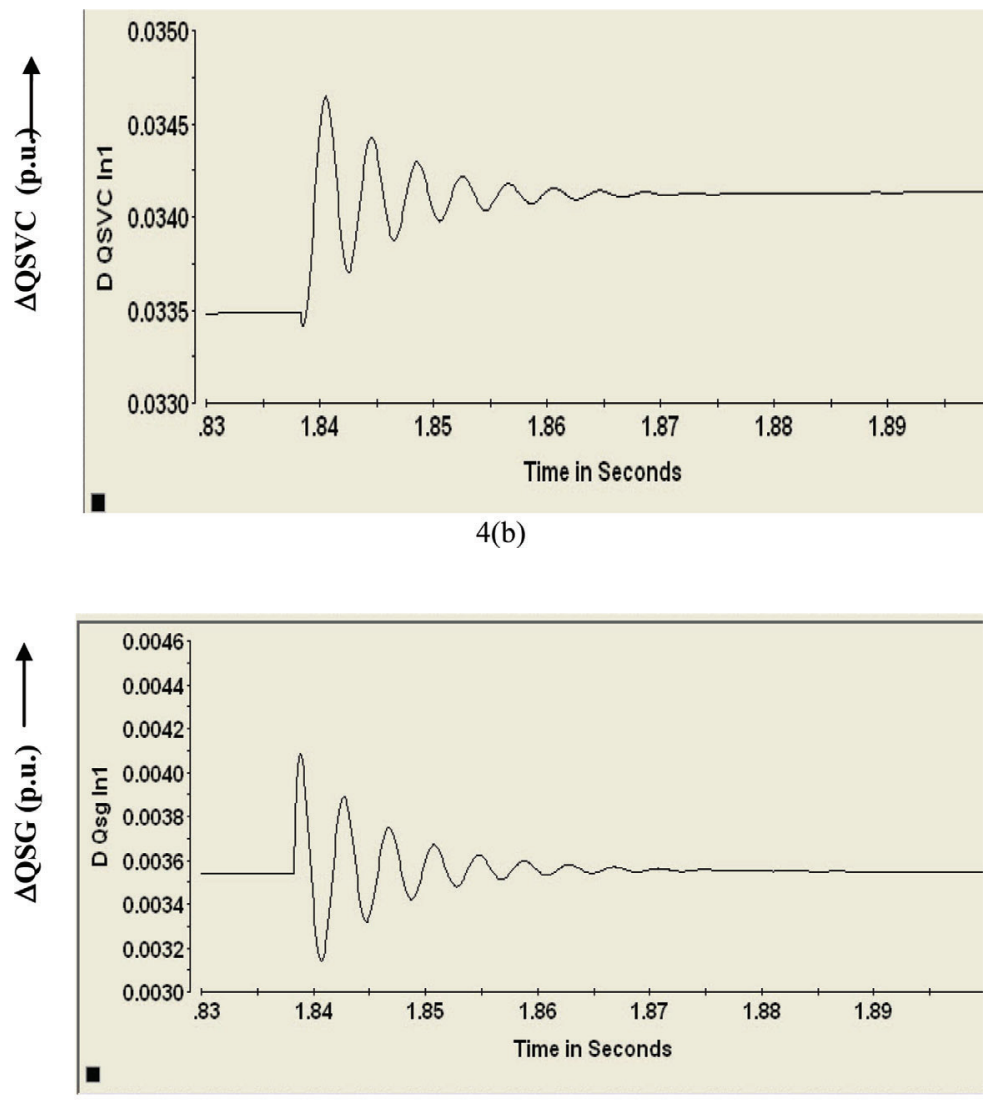

4(c) 

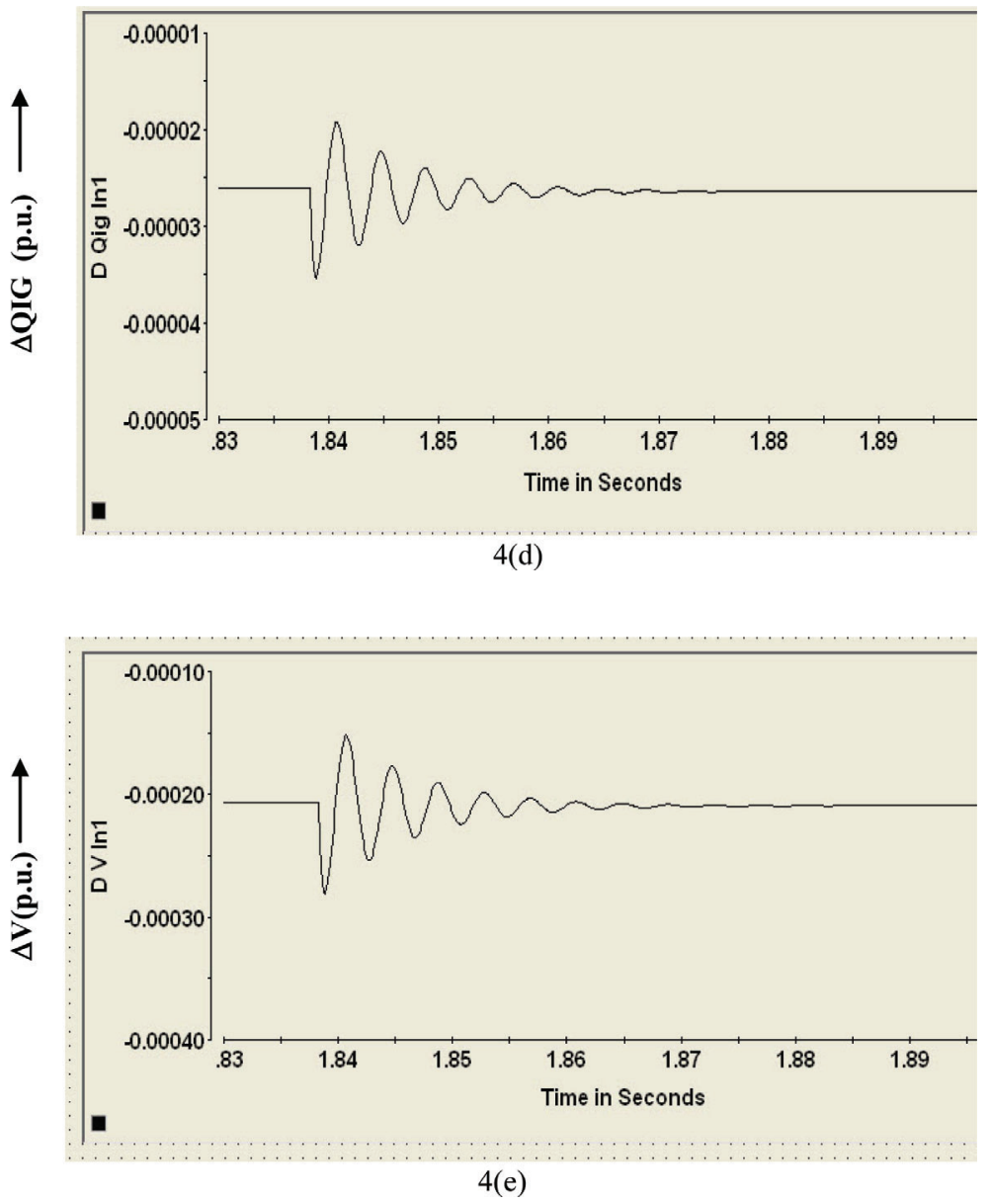

Figure 4 (a to e). Real time responses of the AWDHPS Model - I obtained by MPANN.

\section{Time Domain Specifications}

\subsection{Performance of MPANN in AWDHPS Model - I}

The reactive power load change is a disturbance parameter in the AWDHPS Model - I (It is assumed as a step block). The reactive power load change is compensated by the components such as SVC and SG in the model as given in Equation (1). The reactive power load change is varied from 0.01 to 0.04 p.u. using the knob. The performance curves of various components such as SVC, SG and IG are shown in Figure 4 (a to e). The advantage of real time study is 

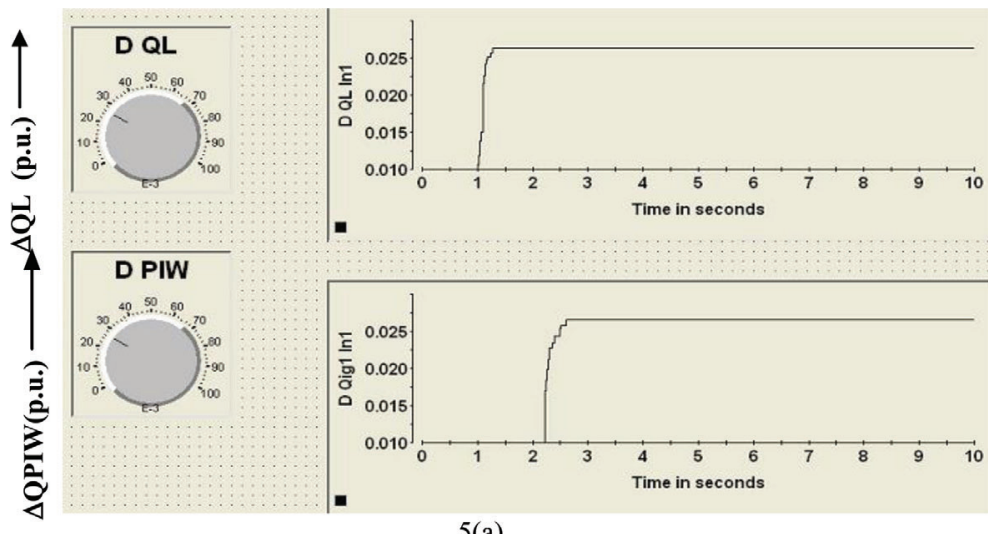

5(a)

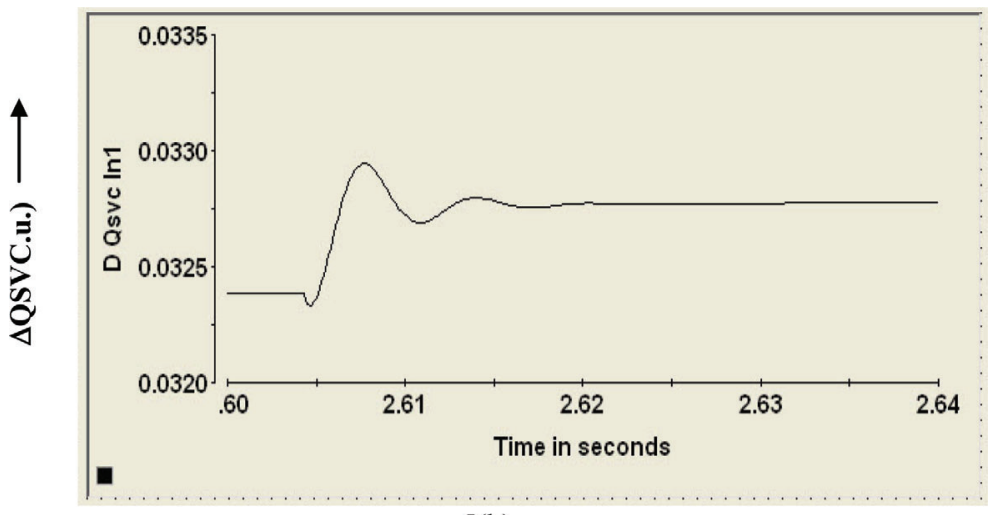

5(b)

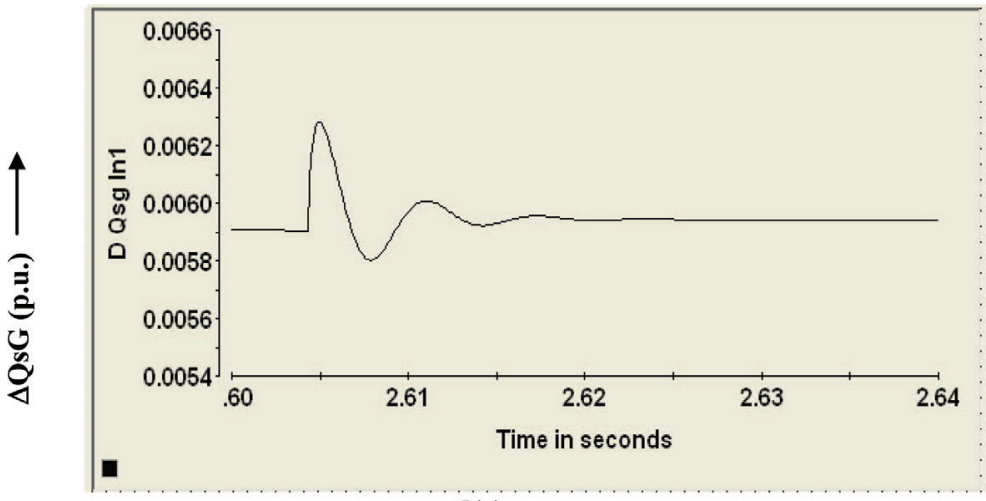

5(c) 


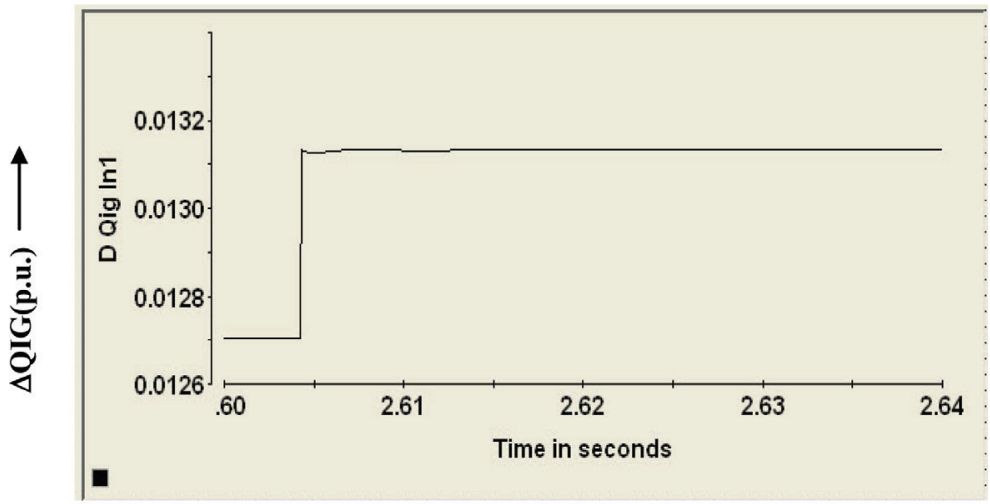

$5(d)$



$5(\mathrm{e})$

Figure 5 (a to e). Real time responses of the AWDHPS Model - II obtained by MPANN.

that reactive power load change is varied from 0.01 to 0.04 p.u. with a time span of $0.85 \mathrm{sec}$ to $1.8 \mathrm{sec}$ and it is visually shown in the Figure 4 (a to e). It is found that the reactive power is supported fully by SVC for the reactive power change whereas the reactive power variations in SG and IG are very less. The performance of voltage variation under step change in load is also an important parameter considered in the study. Hence the time domain response specifications such as percent over shoot, settling time, rise time, peak time and steady state value of SVC for reactive power load changes from 0.01 to 0.1 p.u. were observed. The time domain specifications of SVC obtained by the proposed MPANN controller was compared with a PI controller and 
tabulated in Table 3. It is observed that as the load change occurs from 0.01 to 0.1 p.u. the settling time is reduced at a faster rate by MPANN controller to damp the oscillations. The percentage peak overshoot is very less. Thus the performance of proposed MPANN controller is found to be good.
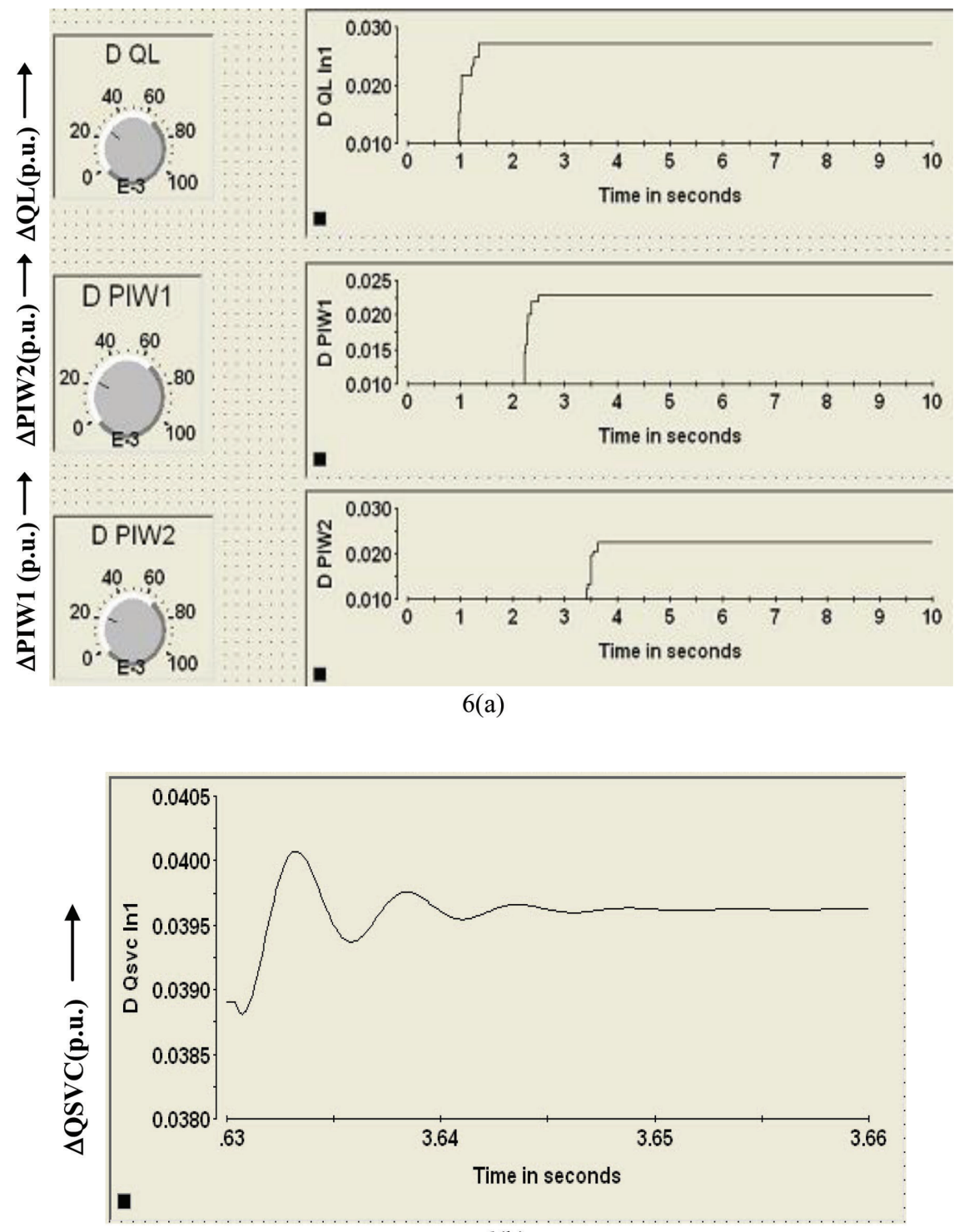

6(b) 
14 P. Sivachandran
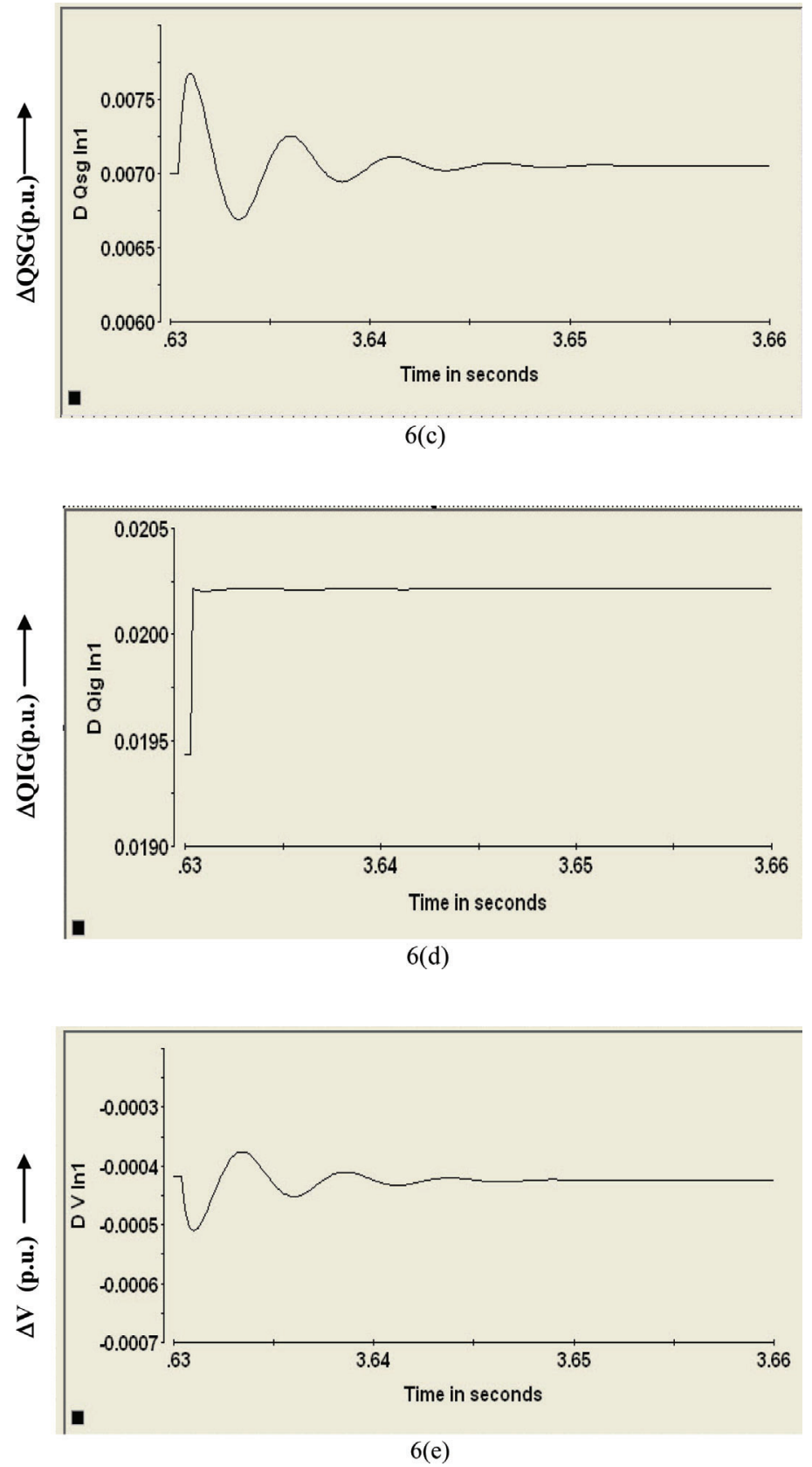

Figure 6 (a to e). Real time responses of the AWDHPS Model - III obtained by MPANN. 
Table 1 Comparison of maximum deviations of parameters of AWDHPS Model - II

\begin{tabular}{llcc}
\hline Parameter of & & For $\eta \mathrm{q}=3.25$ and & For $\eta \mathrm{q}=1.25$ and \\
Model - II & Type of Controller & $\Delta \mathrm{QL}$ (p.u.) $=0.031$ & $\Delta \mathrm{QL}$ (p.u.) $=0.029$ \\
\hline$\Delta \mathrm{V}$ (p.u.) & ANN [3] & -0.001900 & -0.001564 \\
& Proposed MPANN & -0.000160 & -0.000148 \\
$\Delta$ QSG (p.u.) & ANN [3] & 0.0140 & 0.0115 \\
& Proposed MPANN & 0.0052 & 0.0056 \\
$\Delta$ QSVC (p.u.) & ANN [3] & 0.0204 & 0.0202 \\
& Proposed MPANN & 0.0289 & 0.0260 \\
$\Delta$ QIG (p.u.) & ANN [3] & 0.0032 & 0.0032 \\
& Proposed MPANN & 0.003 & 0.003 \\
\hline
\end{tabular}

Table 2 Comparison of maximum deviations of parameters of AWDHPS Model - III

\begin{tabular}{|c|c|c|c|c|}
\hline \multicolumn{2}{|l|}{$\begin{array}{l}\text { Parameters of } \\
\text { Model - III }\end{array}$} & $\begin{array}{l}\text { Type of } \\
\text { Controller }\end{array}$ & $\begin{array}{c}\text { For } \eta q=3.25 \\
\text { and } \Delta \mathrm{QL} \\
\text { (p.u.) }=0.034\end{array}$ & $\begin{array}{c}\text { For } \eta q=1.25 \\
\text { and } \Delta \mathrm{QL} \\
\text { (p.u.) }=0.031\end{array}$ \\
\hline \multirow{2}{*}{\multicolumn{2}{|c|}{$\Delta \mathrm{V}$ (p.u.) }} & ANN [3] & -0.002089 & -0.001708 \\
\hline & & Proposed MPANN & -0.000189 & -0.000173 \\
\hline \multirow{2}{*}{\multicolumn{2}{|c|}{$\Delta \mathrm{QSG}$ (p.u.) }} & ANN [3] & 0.0148 & 0.0121 \\
\hline & & Proposed MPANN & 0.0047 & 0.0041 \\
\hline \multirow{2}{*}{\multicolumn{2}{|c|}{$\Delta \mathrm{QSVC}$ (p.u.) }} & ANN [3] & 0.0215 & 0.0210 \\
\hline & & Proposed MPANN & 0.0308 & 0.0284 \\
\hline \multirow[t]{4}{*}{$\Delta \mathrm{QIG}$ (p.u.) } & $\Delta$ QIG1 (p.u.) & ANN [3] & 0.003 & 0.003 \\
\hline & & Proposed MPANN & 0.003 & 0.003 \\
\hline & $\Delta$ QIG2 (p.u.) & ANN [3] & 0.001 & 0.001 \\
\hline & & Proposed MPANN & 0.001 & 0.001 \\
\hline
\end{tabular}

Table 3 Comparison of Time Domain Specifications of SVC for AWDHPS Model - I

\begin{tabular}{|c|c|c|c|c|c|c|}
\hline$\Delta \mathrm{QL}$ in p.u. & \multicolumn{2}{|c|}{0.01} & \multicolumn{2}{|c|}{0.05} & \multicolumn{2}{|c|}{0.1} \\
\hline Type of & Proposed & & Proposed & & Proposed & \\
\hline Controller & MPANN & PI & MPANN & PI & MPANN & PI \\
\hline $\begin{array}{l}\text { Overshoot } \\
\text { (Mp) } \%\end{array}$ & 4.0421 & 129.7 & 3.9651 & 129.6 & 3.9860 & 101.1 \\
\hline $\begin{array}{l}\text { Settling time } \\
\text { (ts) sec. }\end{array}$ & 0.1487 & 0.216 & 0.1964 & 0.217 & 0.1515 & 0.210 \\
\hline $\begin{array}{l}\text { Rise time } \\
\text { (tr) sec. }\end{array}$ & 0.8375 & $3.9 \mathrm{e}-4$ & 0.8324 & $3.4 \mathrm{e}-4$ & 0.8190 & $6.1 \mathrm{e}-5$ \\
\hline $\begin{array}{l}\text { Peak time, } \\
\text { (tp) sec. }\end{array}$ & 0.1767 & 0.104 & 0.1694 & 0.104 & 0.1491 & 0.104 \\
\hline $\begin{array}{l}\text { Steady state } \\
\text { value (YssI) }\end{array}$ & 0.0072 & 0.010 & 0.0362 & 0.049 & 0.0727 & 0.099 \\
\hline
\end{tabular}




\subsection{Performance of MPANN in AWDHPS Model - II}

The two variable parameters such as change in reactive power load ( $\Delta \mathrm{QL})$ and change in mechanical power input of the induction generator ( $\Delta \mathrm{PIW})$ are considered as step changes in AWDHPS Model - II. The real time study is carried out in such a way that the reactive power load change is varied from 0.01 to 0.04 p.u. with a span of $1 \mathrm{sec}$ to $1.3 \mathrm{sec}$ and $\Delta$ PIW is varied from 0.01 to 0.04 p.u. with a span of 2.2 to $2.65 \mathrm{sec}$. The performance curves of SVC, SG, IG and voltage are shown in Figure 5 (a to e). The obtained response curves of $\triangle \mathrm{QSVC}$ and $\triangle \mathrm{QSG}$ are similar to AWDHPS Model -1 . The variation in wind speed largely influences the response curve of $\Delta$ QIG. The obtained response curve of $\Delta$ QIG is from 0.0127 to 0.01312 p.u. with a span of 2.604 to $2.605 \mathrm{sec}$. The performance of voltage variation is high during reactive power load changes and less during change in mechanical power input of the induction generator respectively. Hence the time domain response specifications such as percent over shoot, settling time, rise time, peak time and steady state value of SVC for reactive power load changes from 0.01 to 0.1 p.u. and change in mechanical power input of the induction generator from 0.01 to 0.06 p.u. were observed. The time domain specifications of SVC obtained by the proposed MPANN controller was compared with a PI controller and tabulated in Table 4. It is observed that as the load change occurs from 0.01 to $0.1 \mathrm{p}$.u. and the reactive power change occurs from 0.01 to 0.06 p.u. settling time is reduced at a faster rate by MPANN controller to damp the oscillations. The percentage peak overshoot is very less. Thus the proposed MPANN controller has shown good performance over the PI controller.

Table 4 Comparison of Time Domain Specifications of SVC for AWDHPS Model - II

\begin{tabular}{|c|c|c|c|c|c|c|}
\hline$\Delta \mathrm{QL}$ in p.u. & \multicolumn{2}{|c|}{0.01} & \multicolumn{2}{|c|}{0.05} & \multicolumn{2}{|c|}{0.1} \\
\hline$\Delta$ PIW in p.u. & \multicolumn{2}{|c|}{0.01} & \multicolumn{2}{|c|}{0.03} & \multicolumn{2}{|c|}{0.06} \\
\hline Type of & Proposed & & Proposed & & Proposed & \\
\hline Controller & MPANN & PI & MPANN & PI & MPANN & PI \\
\hline $\begin{array}{l}\text { Overshoot } \\
\text { (Mp) } \%\end{array}$ & 4.0865 & 129.9 & 3.9725 & 119.7 & 3.9664 & 82.60 \\
\hline $\begin{array}{l}\text { Settling time } \\
\text { (ts) sec. }\end{array}$ & 0.1450 & 0.217 & 0.1290 & 0.215 & 0.1094 & 0.203 \\
\hline $\begin{array}{l}\text { Rise time } \\
\text { (tr) sec. }\end{array}$ & 0.8372 & $3.5 \mathrm{e}-4$ & 0.8357 & $1.4 \mathrm{e}-15$ & 0.8081 & $5.1 \mathrm{e}-4$ \\
\hline $\begin{array}{l}\text { Peak time, } \\
\text { (tp) sec. }\end{array}$ & 0.1763 & 0.104 & 0.1742 & 0.104 & 0.1323 & 0.104 \\
\hline $\begin{array}{l}\text { Steady state } \\
\text { value (YssI) }\end{array}$ & 0.0108 & 0.014 & 0.0216 & 0.074 & 0.0947 & 0.129 \\
\hline
\end{tabular}




\subsection{Performance of MPANN in AWDHPS Model - III}

Three variable parameters are considered in AWDHPS Model - III. The real time study is carried out in such a way that the reactive power load change is varied from 0.01 to 0.04 p.u. with a span of $0.96 \mathrm{sec}$ to $1.4 \mathrm{sec}, \Delta$ PIW1 is varied from 0.01 to 0.04 p.u. with a span of 2.2 to $2.5 \mathrm{sec}$ and $\Delta$ PIW2 is varied from 0.01 to 0.04 p.u. with a span of 3.4 to $3.6 \mathrm{sec}$. The performance curves of SVC, SG, IG and voltage are shown in Figure 6 (a to e). The obtained response curves of $\triangle \mathrm{QSVC}$ and $\triangle \mathrm{QSG}$ are similar to AWDHPS Model - I and II. The entire study is carried out in the time span $0.85 \mathrm{sec}$. to $3.6 \mathrm{sec}$. The reactive power ratings of two induction generators are 0.13 and 0.04 p.u. respectively. Based on the rating of the induction generators, it is better to consider the variation of $\Delta \mathrm{PIW} 1$ as higher value than $\Delta \mathrm{PIW} 2$. Hence, in the study, $\Delta$ PIW1 is varied from 0.01 to 0.06 p.u. and $\Delta$ PIW2 is varied from 0.03 to 0.08 p.u. Moreover the reactive power load changes from 0.01 to 0.1 p.u. are considered. The time domain response specifications such as rise time, settling time, percent over shoot, peak time and steady state value of SVC for above variations were observed. The time domain specifications of SVC obtained by the proposed MPANN controller was compared with a PI controller and tabulated in Table 5. The performance of proposed MPANN controller is found to be better than PI controller. From the time domain response specifications of SVC of the three models given in Tables 3, 4 and 5 it is observed that peak time (tp) are nearly same. The percentage of peak overshoot is reduced when $\Delta \mathrm{QL}$ is varied from 0.01 to $1 \mathrm{p} . \mathrm{u}$. because the maximum reactive power

\begin{tabular}{|c|c|c|c|c|c|c|}
\hline$\Delta \mathrm{QL}$ in p.u. & \multicolumn{2}{|c|}{0.01} & \multicolumn{2}{|c|}{0.05} & \multicolumn{2}{|c|}{0.1} \\
\hline$\Delta$ PIW1 in p.u. & \multicolumn{2}{|c|}{0.01} & \multicolumn{2}{|c|}{0.03} & \multicolumn{2}{|c|}{0.06} \\
\hline$\Delta$ PIW2 in p.u. & \multicolumn{2}{|c|}{0.03} & \multicolumn{2}{|c|}{0.05} & \multicolumn{2}{|c|}{0.08} \\
\hline Type of & Proposed & & Proposed & & Proposed & \\
\hline Controller & MPANN & PI & MPANN & PI & MPANN & PI \\
\hline $\begin{array}{l}\text { Overshoot } \\
\text { (Mp) } \%\end{array}$ & 4.0865 & 129.9 & 3.9725 & 119.7 & 3.9664 & 82.60 \\
\hline $\begin{array}{l}\text { Settling time } \\
\text { (ts) sec. }\end{array}$ & 0.1450 & 0.217 & 0.1290 & 0.215 & 0.1094 & 0.203 \\
\hline $\begin{array}{l}\text { Rise time } \\
\text { (tr) sec. }\end{array}$ & 0.8372 & $3.5 \mathrm{e}-4$ & 0.8357 & $1.4 \mathrm{e}-15$ & 0.8081 & $5.1 \mathrm{e}-4$ \\
\hline $\begin{array}{l}\text { Peak time, } \\
\text { (tp) sec. }\end{array}$ & 0.1763 & 0.104 & 0.1742 & 0.104 & 0.1323 & 0.104 \\
\hline $\begin{array}{l}\text { Steady state } \\
\text { value (YssI) }\end{array}$ & 0.0108 & 0.014 & 0.0216 & 0.074 & 0.0947 & 0.129 \\
\hline
\end{tabular}


supported by SVC is assumed to be 0.85 p.u. Generally the rise time (tr) increases as $\Delta \mathrm{QL}$ is varied from 0.01 to 1 p.u. in all the three models. In the case of increase in $\Delta \mathrm{QL}$ and $\Delta \mathrm{PIW}$ the settling time (ts) decreases. The steady state value (YSS) of SVC in AWDHPS Model - III is high because of the cumulative effect of three variable parameters of the model. Hence it is represented in a simple way by the expression, YssI $<$ YssII $<$ YssIII. Thus the AWDHPS Models are simulated in dSPACE environment and in this study the Knob is varied to increase or decrease the reactive power load and mechanical power of induction generators in real time environment for a desired time specification. The performance curves are visualized for the various components present in the models.

\section{Conclusion}

This paper presented the automatic reactive power control of AWDHPS by tuning SVC using the proposed MPANN. The MATLAB/simulink models of three different AWDHPS were built by integrating the proposed MPANN as the controller for tuning the SVC. The potential of proposed MPANN controller was demonstrated by varying the disturbance parameters such as change in reactive power of the load $(\Delta \mathrm{QL})$, the change in mechanical power input of single induction generator ( $\triangle \mathrm{PIW}$ ) and the change in mechanical power input of two induction generators ( $\triangle \mathrm{PIW} 1, \Delta \mathrm{PIW} 2)$ in three different AWDHPS models. Then the above MATLAB/simulink models of AWDHPS were built in dSPACE real time environment. The real time assessment of the models was carried out by dynamically varying the parameters in control desk of dSPACE Software with DS1104 R \& D controller board mounted in personal computer. The proposed MPANN controller in dSPACE environment has performed well compared to the ANN controller in MATLAB/simulink present in recent literature. Specifically the change in system voltage $(\Delta \mathrm{V})$ was significantly reduced by the MPANN controller. The time domain specifications of SVC obtained by the MPANN controller and a PI controller were compared. The proposed MPANN controller has shown good performance over the PI controller. The static and dynamic response curves were depicted. The reactive power deviations and time domain specifications were tabulated. 


\section{Appendix A: AWDHPS Data}

\begin{tabular}{|c|c|c|c|}
\hline \multirow[t]{2}{*}{ AWDHPS Parameters } & \multirow[t]{2}{*}{$\begin{array}{c}\text { AWDHPS } \\
\text { data - I }\end{array}$} & \multicolumn{2}{|c|}{$\begin{array}{c}\text { AWDHPS } \\
\text { data - II }\end{array}$} \\
\hline & & IG1 & IG2 \\
\hline Wind Capacity (kW) & 150 & 150 & 50 \\
\hline Diesel Capacity (kW) & 150 & 150 & - \\
\hline Load Capacity (kW) & 250 & & 300 \\
\hline Base Power (kVA) & 250 & & 300 \\
\hline \multicolumn{4}{|l|}{ SG: } \\
\hline PSG (pu kW) & 0.4 & & 0.333 \\
\hline QSG (pu kVAR) & 0.2 & & 0.162 \\
\hline $\mathrm{Eq}{ }^{\prime}(\mathrm{pu})$ & 1.1136 & & 0.9804 \\
\hline$\delta \mathrm{o}$ & 21.05 & & 17.2483 \\
\hline $\mathrm{Eq}(\mathrm{pu})$ & 0.9603 & & 1.1242 \\
\hline $\mathrm{V}(\mathrm{pu})$ & 1.0 & & 1.0 \\
\hline $\mathrm{xd}(\mathrm{pu})$ & 1.0 & & 1.0 \\
\hline $\mathrm{x}^{\prime} \mathrm{d}(\mathrm{pu})$ & 0.15 & & 0.15 \\
\hline T'do (pu) & 5.0 & & 5.0 \\
\hline \multicolumn{4}{|l|}{ IG: } \\
\hline$\overline{\mathrm{PIG}}(\mathrm{pu} \mathrm{kW})$ & 0.6 & 0.5 & 0.1667 \\
\hline QIG (pu kVAR) & 0.189 & 0.1343 & 0.0426 \\
\hline PIW (pu kW) & 0.75 & 0.63 & 0.21 \\
\hline$\eta \operatorname{IG}(\%)$ & 80 & 80 & 80 \\
\hline $\mathrm{r} 1=\mathrm{r} 2^{\prime}(\mathrm{pu})$ & 0.19 & 0.19 & 0.55 \\
\hline $\mathrm{x} 1=\mathrm{x} 2^{\prime}(\mathrm{pu})$ & 0.56 & 0.56 & 1.6 \\
\hline $\mathrm{s}(\%)$ & -4.1 & -3.49 & -3.37 \\
\hline \multicolumn{4}{|l|}{ Load: } \\
\hline$\overline{\mathrm{PL}(\mathrm{pu} \mathrm{kW})}$ & 1.0 & & 1.0 \\
\hline QL (pu kVAR) & 0.75 & & 0.75 \\
\hline $\mathrm{Pf}(\mathrm{lag})$ & 0.8 & & 0.8 \\
\hline \multicolumn{4}{|l|}{ SVC: } \\
\hline QSVC (pu kVAR) & 0.739 & & 0.7649 \\
\hline QC (pu kVAR) & 0.85 & & 0.87961 \\
\hline$\alpha$ (radians) & 2.443985 & & 2.4452 \\
\hline $\mathrm{T} \alpha(\mathrm{s})$ & 0.005 & & 0.005 \\
\hline $\mathrm{Td}(\mathrm{s})$ & 0.001667 & & 0.00167 \\
\hline \multicolumn{4}{|c|}{ IEEE Type-I Excitation System: } \\
\hline KA & 40 & & 40 \\
\hline $\mathrm{TA}(\mathrm{s})$ & 0.05 & & 0.05 \\
\hline $\mathrm{KF}$ & 0.5 & & 0.5 \\
\hline $\mathrm{TF}(\mathrm{s})$ & 0.715 & & 0.715 \\
\hline $\mathrm{KE}$ & 1.0 & & 1.0 \\
\hline $\mathrm{SF}(\mathrm{s})$ & 0.0 & & 0.0 \\
\hline TE $(s)$ & 0.55 & & 0.55 \\
\hline
\end{tabular}




\title{
Appendix B: Constant Values of AWDHPS
}

\author{
AWDHPS Model - I: \\ $\mathrm{K} 1=0.15 ; \mathrm{K} 2=0.793232 ; \mathrm{K} 3=6.22143 ; \mathrm{K} 4=-7.358895 ; \mathrm{K} 5=0.126043 ;$ \\ $\mathrm{K} 8=1.478 ; \mathrm{K} 9=1.0 ; \mathrm{KV}=0.6667 ; \mathrm{K} \alpha=0.446423$ and \\ $\mathrm{TV}=0.000106$ seconds.
}

AWDHPS Model - II:

$\mathrm{K} 1=0.15 ; \mathrm{K} 2=0.793232 ; \mathrm{K} 3=6.22143 ; \mathrm{K} 4=-7.35889, \mathrm{~K} 6=0.4961$;

$\mathrm{K} 7=-0.122068 ; \mathrm{K} 8=1.478 ; \mathrm{K} 9=1.0, \mathrm{KV}=0.6667 ; \mathrm{K} \alpha=0.446423$

and $\mathrm{TV}=0.000106$ seconds.

\section{AWDHPS Model - III:}

$\mathrm{K} 1=0.15 ; \mathrm{K} 2=0.811744 ; \mathrm{K} 3=6.36662 ; \mathrm{K} 4=-7.0915, \mathrm{~K} 61=0.4961$;

$\mathrm{K} 62=0.39575 ; \mathrm{K} 71=-0.122068 ; \mathrm{K} 72=-0.026977 ; \mathrm{K} 8=1.52976$;

$\mathrm{K} 9=1.0 ; \mathrm{KV}=0.66667$, and $\mathrm{TV}=0.0001061$ seconds.

\section{References}

[1] Elhadidy, M. A., and Shaahid, S. M. (2005). Decentralized/stand-alone hybrid Wind-Diesel power systems to meet residential loads of hot coastal regions. Int. J. Energy Convers. Manag. 46, 2501-2513.

[2] Bansal, R. C., Zobaa, A. F., and Saket, R. K. (2005). Some issues related to power generation using wind energy conversion systems: an overview. Int. J. Emerg. Electr. Power Syst. 3, 1-17.

[3] Bansal, R. C., and Bhatti, T. S. (2008). Small Signal Analysis of Isolated Hybrid Power Systems: Reactive Power and Frequency Control Analysis. New Delhi: Narosa Publishing House.

[4] Juan Dixon et al. (2005). "Reactive power compensation technologies: state-of-the-art review," in Proceedings of the IEEE, Vol. 93, 2144-2164.

[5] Hingorani, N. G. (2000). Understanding FACTS: Concepts and Technology of Flexible AC Transmission Systems. Piscataway, NJ: IEEE Press.

[6] Sharma, P., Hoff, B., and Meena, R. (2014). "ANN based reactive power control of an autonomous wind-diesel hybrid power plant using PMIG and SG," in Proceedings of IEEE Conference on Power and Energy Systems: Towards Sustainable Energy (Bangalore: IEEE), 1-6. doi: 10.1109/PESTSE.2014.6805263 
[7] Niebur, D. (1993). Neural networks applications in power systems. Int. J. Eng. Intell. Syst. 3, 133-158.

[8] Al-Alawi, S. M., and Ellithy, K. A. (2000). Tuning of SVC damping controllers over a wide range of load models using an artificial neural network. Int. J. Electr. Power Energy Syst. 22, 405-420.

[9] Kalogirou, S. A. (1999). Applications of artificial neural networks in energy systems: a review. Int. J. Energy Convers. Manag. 40, 1073-1087.

[10] Mihet-Popa, L., Groza, V., Prostean, O., and Szeidert, I. (2008). "Modeling and design of a grid connection control mode for a small variablespeed wind turbine system," in Proceedings of the IEEE International Instrumentation and Measurement Technology Conference, Victoria, $\mathrm{BC}$, Canada.

[11] Esmaeilian, H. R., and Bahramjerdi, R. F. (2017). "A remedy for mitigating voltage fluctuations in small remote wind-diesel systems using network theory concepts," in Proceedings of the IEEE Transactions on Smart Grid, Vol. 99 (Rome: IEEE). doi: 10.1109/TSG.2017.2652438

[12] Singh, B., Murthy, S. S., and Gupta, S. (2006). STATCOM-based voltage regulator for self-excited induction generator feeding nonlinear loads. IEEE Trans. Ind. Electron. 53, 1437-1452.

[13] Deshmukh, S., Natarajan, B., and Pahwa, A. (2012). Voltage or VAR control in distribution networks via reactive power injection through distributed generators. IEEE Trans. Smart Grid 3, 1226-1234.

[14] Mohanty, A., Patra, S., and Ray, P. K. (2016). Robust fuzzy-sliding mode based UPFC controller for transient stability analysis in autonomous wind-diesel-PV hybrid system. IET Gener. Transm. Distrib. 10, 1248-1257. doi: 10.1049/iet-gtd.2015.1000

[15] Lee, D. J., and Wang, L., (2008). Small signal stability analysis of an autonomous hybrid renewable energy power generation/energy storage system part I: time domain simulations. IEEE Trans. Energy Convers. 23, 311-320.

[16] Roy, S. (2010). Reduction of voltage dynamics in isolated wind-diesel units susceptible to gusting. IEEE Trans. Sustain. Energy 1, 84-91.

[17] Lukasievicz, T., Oliveira, R. V., and Dranka, G. G. (2015). "Control of an islanded wind-diesel microgrid with high penetration level of wind generation," in Proceedings of the Power Energy Society General Meeting (Denver, CO: IEEE), 1-5.

[18] Theubou, T. A., Wamkeue, R., and kamwa, I. (2012). "Reactive power management modeling of an autonomous wind-diesel power plant," 
in Proceedings of the IECON 2012-38th Annual Conference on IEEE Industrial Electronics Society (Montreal, QC: IEEE), 4326-4331.

[19] Elkhatib, M. E., Shatshat, R. E., and Salama, M. M. A. (2012). Decentralized reactive power control for advanced distribution automation systems. IEEE Trans. Smart Grid 3, 1482-1490.

[20] Saha, T. K., and Kastha, D. (2010). Design optimization and dynamic performance analysis of a standalone hybrid wind-diesel electrical power generation system. IEEE Trans. Energy Convers. 25, 1209-1217.

[21] Kassem, A. M., and Abdelaziz, A. Y. (2014). Reactive power control for voltage stability of standalone hybrid wind-diesel power system based on functional model predictive control. IET Renew. Power Gener. 8, 887-899. doi: 10.1049/iet-rpg.2013.0199

[22] Simpson-Porco, J. W., Shafiee, Q., Dorfler, F., Vasquez, J. C., Guerrero, J. M., and Bullo, F. (2015). Secondary frequency and voltage control of islanded microgrids via distributed averaging. IEEE Trans. Ind. Electron. 62, 7025-7038.

[23] Baudoin, S., Vechiu, I., and Camblong, H. (2012). "A review of voltage and frequency control strategies for islanded microgrid," in Proceedings of the IEEE International Conference on System Theory, Control and Computing (Sinaia: IEEE), 1-5.

[24] Mi, Y., et al. (2017). The SVC additional adaptive voltage controller of isolated wind-diesel power system based on double sliding mode optimal strategy. IEEE Trans. Sustain. Energy 99, 1-10.

[25] Sosnina, E., Shalukho, A., and Lipuzhin, I. (2014). "Research of isolated electrical systems stability with wind-diesel hybrid power stations," in Proceedings of the IEEE International Conference on Industrial Engineering 2016 (Chelyabinsk: IEEE), 1-6.

[26] Banerjee, A., Mukherjee, V., and Ghoshal, S. P. (2014). Intelligent fuzzybased reactive power compensation of an isolated hybrid power system. Int. J. Electr. Power Energy Syst. 57, 164-177. 


\section{Biography}

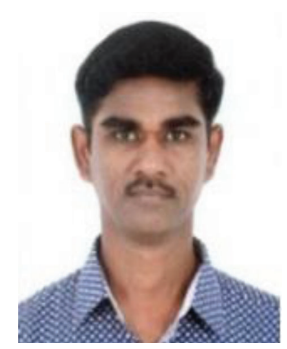

Dr. P. Sivachandran received his B.E. Electrical and Electronics Engineering and M.E. Power Electronics and Drives in 1996 and 1999 respectively, from the Bharathidasan University, India. He received his Ph.D. Electrical Engineering in 2012 from Anna University, Chennai, India. He has received a Young Scientist Fellowship Award from Tamilnadu State Council for Science and Technology, Government of Tamilnadu, India. He has received an International Travel Grant from Department of Science and Technology, Government of India to present a research paper in IEEE ICSET 2008 at Singapore. His areas of research include design and development of permanent magnet generator for wind energy systems, real time performance study of hybrid energy systems, hybrid electric vehicles and analysis of claw-pole alternators. He has published research papers in International Journals and International Conferences. He has seventeen years of teaching experience and two years of industrial R\&D experience. Presently he is working as Professor, Department of Electrical and Electronics Engineering, Vel Tech Multi Tech Dr. Rangarajan Dr. Sakunthala Engineering College, Chennai, India. 
